\title{
Treatment of myofascial trigger points of the infraspinatus is effective in relieving shoulder pain and improving shoulder functions: A randomized clinical trial
}

\section{Sungeon Park}

Graduate School of Sahmyook University

Joochul Cho

Graduate School of Sahmyook University

Seungwon Lee ( $\nabla$ swlee@syu.ac.kr)

Sahmyook University https://orcid.org/0000-0002-0413-0510

\section{Research article}

Keywords: infraspinatus, trigger point, low level laser, acupressure

Posted Date: January 21st, 2020

DOl: https://doi.org/10.21203/rs.2.21424/v1

License: (c) (i) This work is licensed under a Creative Commons Attribution 4.0 International License.

Read Full License 


\section{Abstract}

Background This study aimed to investigate the effects of ischemic compression treatment (ICT) and low-level laser therapy (LLLT) applied on the trigger points of the infraspinatus muscle on shoulder pain and function in patients with shoulder pain.

Methods Thirty patients with shoulder pain were randomly categorized into the ICT group $(n=15)$ and LLLT groups $(n=15)$. ICT was performed on three myofascial trigger points (MTrPs) of the infraspinatus muscle twice a week for 4 weeks (eight sessions), with 5 minutes of treatment per trigger point. LLLT was performed similarly. Shoulder pain was assessed using the visual analogue scale (VAS) and pain pressure threshold (PPT), and shoulder function was assessed using the Korean Disabilities of the Arm, Shoulder and Hand (DASH) questionnaire, rotator cuff strength, and range of motion (ROM) of shoulder flexion and abduction.

Results Significant changes in VAS score and PPT were found after the intervention in both groups $(\mathrm{p}<$ 0.05). Significant changes were observed in the Korean DASH score, rotator cuff strength, and ROM of shoulder flexion $(p<0.05)$ but not in the ROM of shoulder abduction $(p<0.05)$. There were no significant differences between the two groups.

Conclusion This study showed that both ICT and LLLT applied on the MTrPs of the infraspinatus muscle were effective for relieving shoulder pain and improving shoulder functions in patients with shoulder pain.

\section{Background}

As one of the muscles of the rotator cuff, the main function of the infraspinatus muscle is to externally rotate the glenohumoral joint and provide stability (1). This muscle is easily influenced by movement involving the hands. Sporrong et al. (1998) reported that the infraspinatus muscle shows higher muscle activity than other shoulder muscles during manual work (2), and Jarvholm et al. (1989) reported that excessive use of the hand increases intramuscular pressure in the shoulders, leading to clear changes in infraspinatus muscle activity $(3,4)$. In addition, Birch et al. $(2000)$ stated that computer work requiring concentration also impacts the infraspinatus muscle (5).

Infraspinatus tendon injury is common and, when coupled with subscapularis tendon injury, it may disturb the balance of anteroposterior strength of the shoulder joint (6). An imbalance of strength alters the position of the humeral head $(7,8)$ and may induce secondary articular injuries, such as articular cartilage degeneration, rotator cuff tear, and injury of the long head of biceps (9). Although these studies were unable to confirm the exact mechanism, they found an association between the infraspinatus muscle and shoulder pain.

Muscle pain seems to be related to myofascial trigger points (MTrPs) (10). MTrPs refer to a taut band formed in a stiff muscle that induces myofascial pain, and are known to be a common cause of 
musculoskeletal pain(11). The exact pathophysiology of MTrPs is as yet unclear, but the possibility of local metabolic disturbance caused by abnormal electrical activity known as endplate noise, altered muscle activities, and blood circulation disturbance has been proposed (12).

Various treatments are applied for MTrPs, as the exact etiology and healing mechanism are currently unknown (13). Of these, ischemic compression is the most common treatment for MTrPs. This treatment mitigates pain and radiating pain, improves limited range of motion (ROM), and facilitates recovery of muscle functions (14). In addition, recent studies have applied low-level laser therapy (LLLT) to MTrPs (15). LLLT, such as He-Ne laser and infrared laser, do not injure tissues and are utilized to treat pain of various causes.

Although relevant studies are still lacking, treatment of MTrPs is expected to be helpful for patients with shoulder pain (16-18). In particular, treatment of MTrPs of the infraspinatus muscle is expected to have clinical efficacy for shoulder pain. Simons (1999) and Skootsky (1989) reported that MTrPs frequently occur in the infraspinatus and upper trapezius and that the infraspinatus is particularly associated with myofascial pain related to the shoulder joint $(19,20)$ Furthermore, Hains et al. $(2010)$ also reported that removing MTrPs in the shoulder could facilitate recovery of shoulder function and relieve pain (21).

From the above, treating MTrPs of the infraspinatus is expected to be clinically effective in treating shoulder pain. However, most previous studies treated MTrPs of muscles related to shoulder pain instead of applying treatment based on an accurate diagnosis, so may have unintentionally affected irrelevant MTrPs (10). Further, studies comparing ischemic compression and LLLT, which are effective on MTrPs, are also scarce.

Therefore, this study aims to apply treatment specifically targeting MTrPs of the infraspinatus, without affecting MTrPs of other muscles as much as possible and identify the effects on shoulder pain and function. Moreover, we aim to propose an efficient treatment method for the shoulder by comparing the effects of ischemic compression treatment (ICT) and LLLT.

\section{Method}

\subsection{Study design}

A pretest-posttest two group design was used including patients who visited a hospital in Seoul between July 31, 2017 and August 26, 2017. This study registered in Clinical Research information Service(CRIS) with clinical trial registry number KCT0004576. The project is in accordance with the ethical principles and national norms and standards approved by the Bioethics committee of Sahmyook University (IRB number: 2-1040781-AB-N-01-2017063HR/ June 22, 2017)

\subsection{Participants}

The inclusion criteria were patients 20-50 years of age who had non-traumatic shoulder pain for at least six months, had a Korea version of the Disability of the Arm, Shoulder and Hand (K-DASH) score of 15 or 
higher, had trigger points in the infraspinatus muscle, and had both shoulder pain and reduced range of motion (ROM) $(22,23)$.

The exclusion criteria were history of shoulder surgery or severe shoulder trauma, referred pain in the shoulder due to a heart disease, mental disease, radiculopathy, or neuropathy (23).

\subsection{Sample size}

The sample size required for the purpose of this study was calculated using the G*Power program 3.1.9.2. Significance level was set at 0.05 . The mean treatment effect size of 1.06 on cervical spine ROM was applied to our study with reference to the study by Ravichandran et al. (2016). Considering a 10\% dropout rate, 34 participants were recruited (24).

\subsection{Randomization}

The physical therapist involved in this study allocated randomly eligible 30 participants into the ICT group and LLLT group using the randomization feature on SPSS. Randomized patients received ICT and LLLT respectively during the study period according to the intervention they were allocated. Patients were blinded to treatment allocation.

\subsection{Study procedure}

The participants were divided into an ICT group and LLLT group, and the interventions were administered in 15 minute sessions, twice a week for four weeks for a total of eight sessions from July 31, 2017 to August 26, 2017.

After recruiting 34 patients with shoulder pain, their Visual Analogue Scale (VAS), pressure-pain threshold (PPT), and K-DASH scores were assessed prior to the study. Two patients were excluded per the inclusion criteria, and another two were excluded for personal reasons (moving and absence). A physical therapist with at least five years of clinical experience who thoroughly understood the overall study procedure and had experience with trigger point treatment in the past administered the trigger point treatment and LLLT.

\subsection{Interventions}

Ischemic compression treatment (ICT)

Trigger points were identified using the palpation technique. Startling, involuntary muscle contraction due to tenderness, and radiating pain when the therapist applied pressure with the thumb were considered positive responses.

With the participant lying comfortably on the stomach, the therapist first lightly pressed on the trigger points of the infraspinatus muscle. Then, the pressure was increased to a level eliciting endurable pain and maintained for 30 seconds followed by a 30 -second rest. The treatment was applied for five repetitions lasting five minutes for each of the trigger points 1,2 , and 3 of the infraspinatus, for a total of 15 minutes (Fig. 1)(22). 
The low-level laser (STL-101, Stratek, Korea, 2004) used in this study was a diode laser with a $650 \mathrm{~nm}$ wavelength and $50 \mathrm{~mW}$ power. With the participant lying comfortably on the stomach, the low-level laser was applied for five minutes to each of the trigger points 1, 2, and 3 of the infraspinatus, for a total of 15 minutes. The diameter of the laser was adjusted to $0.5 \mathrm{~cm}(25)$.

\section{Outcome Measure}

Shoulder pain was measured using VAS and PPT. Shoulder functions were measured based on ROM, KDASH, and rotator cuff strength.

\subsection{Pain}

Pain was assessed using VAS and PPT. PPT was measured with an algometer (Fabrication enterprises, USA, 2010). With the participant seated comfortably, the examiner identified the participant's trigger point in the infraspinatus muscle and applied pressure with the algometer perpendicular to the skin surface until the participant made an "Ah" sound. Three measurements were taken and the mean was used for analysis (26).

\subsection{Function}

Active ROM of the shoulder joint was measured using a goniometer (HiRes, USA, 2008). In the present study, shoulder movements frequently used in daily living (shoulder flexion, abduction), as opposed to the functional movements of the infraspinatus muscle, were measured. Flexion and abduction were measured with the participant in a standing position. Three measurements were taken and the mean was used for analysis.

The K-DASH was used to assess the ability to perform activities. The K-DASH questionnaire consists of 38 items, with 30 items related to the disability/symptom, four items related to work, and four items related to sport/art activities. In the present study, only the disability/symptom scale was used.

Finally, rotator cuff strength was measured using a portable dynamometer (digital hand dynamometer, EH101, TNI Commerce, China, 2011). With the participant sitting down, hand grip strength was measured three times in $90^{\circ}$ abduction and $90^{\circ}$ external rotation and the mean was used for analysis (Fig. 2)(27).

\section{Analysis}

All work and statistical analyses in the present study were performed using SPSS ver. 21.0. The kolmogorove-Smirnov test was performed for the study population to test for normality assumption and all variables were normally distributed. Intergroup differences were analyzed with independent t-tests. Differences after treatment were analyzed with paired t-tests. For withdrawn participants, intention to treat(ITT) was measured using the last observation carried forward (LOCF) method, where the values 
observed immediately prior to withdrawal were used as the final values. Statistical significance was set at 0.05 for all data.

\section{Results}

\subsection{General characteristics and homogeneity testing}

Both the ICT and LLLT groups were found to be homogeneous in terms of general characteristics. A total of 30 individuals participated in this study, with 15 in the ICT group and 15 in the LLLT group. The mean age was 36.49 years in the ICT group and 32.60 years in the LLLT group, with no significant differences between the two groups. The mean height was $166.26 \mathrm{~cm}$ in the ICT group and $168.00 \mathrm{~cm}$ in the LLLT group and the mean body weight was $63.06 \mathrm{~kg}$ in the ICT group and $65.47 \mathrm{~kg}$ in the LLLT group, showing no significant differences in height or body weight between the two groups (Table 1).

Table 1

Participants' general characteristics

\begin{tabular}{|llll|}
\hline Parameter & $\begin{array}{l}\text { ICT } \\
(\mathbf{n}=\mathbf{1 5})\end{array}$ & $\begin{array}{l}\text { LLLT } \\
(\mathbf{n}=\mathbf{1 5})\end{array}$ & $\begin{array}{l}\text { P value } \\
\text { (intergroup values) }\end{array}$ \\
\hline Sex (male/female) & $5 / 10$ & $7 / 8$ & \\
\hline Age (years) & $36.49(9.66)$ & $32.60(6.33)$ & 0.213 \\
\hline Height (cm) & $166.26(8.11)$ & $168.00(5.35)$ & 0.496 \\
\hline Body weight (kg) & $63.06(11.74)$ & $65.47(9.23)$ & 0.539 \\
\hline $\begin{array}{l}\text { ICT, ischemic compression treatment; LLLT, low level laser treatment } \\
\text { Values are shown as mean (standard deviation) }\end{array}$ \\
\hline
\end{tabular}

Pain was measured using the VAS and PPT. In the ICT group, VAS significantly decreased by 2.73 from 5.53 before treatment to 2.8 after treatment $(p<0.05)$, while PPT significantly increased by $0.31 \mathrm{~kg}$ from $3.84 \mathrm{~kg}$ before treatment to $4.15 \mathrm{~kg}$ after treatment $(p<0.05)$. In the LLLT group, VAS significantly decreased by 2.20 from 5.67 before treatment to 3.47 after treatment $(p<0.05)$, while PPT significantly increased by $0.25 \mathrm{~kg}$ from 3.89 before treatment to $4.14 \mathrm{~kg}$ after treatment $(p<0.05)$. There were statistically significant differences in pain after treatment between the two groups (Table 2). 
Table 2

Changes in shoulder pain after ICT and LLLT

\begin{tabular}{|c|c|c|c|c|c|c|c|c|}
\hline & \multicolumn{4}{|l|}{ ICT } & \multicolumn{4}{|l|}{ LLT } \\
\hline & Pre & Post & Change & $\mathrm{d}[\mathrm{Cl}]$ & Pre & Post & Change & $\mathrm{ES}[\mathrm{Cl}]$ \\
\hline \multicolumn{9}{|l|}{ Pain } \\
\hline VAS & $\begin{array}{l}5.53 \\
(1.06)\end{array}$ & $\begin{array}{l}2.80 \\
(0.94)\end{array}$ & $\begin{array}{l}2.73 \\
(1.27)^{*}\end{array}$ & $\begin{array}{l}2.54[2.0 \\
\text { to } 3.44]\end{array}$ & $\begin{array}{l}5.53 \\
(0.92)\end{array}$ & $\begin{array}{l}3.33 \\
(0.72)\end{array}$ & $\begin{array}{l}2.20 \\
(1.14)^{\star}\end{array}$ & $\begin{array}{l}2.66 \\
{[1.56} \\
\text { to } \\
2.83]\end{array}$ \\
\hline PPT & $\begin{array}{l}3.84 \\
(0.57)\end{array}$ & $\begin{array}{l}4.17 \\
(0.47)\end{array}$ & $\begin{array}{l}0.30 \\
(0.41)^{*}\end{array}$ & $\begin{array}{l}0.63[-0.53 \\
\text { to }-0.07]\end{array}$ & $\begin{array}{l}3.89 \\
(0.61)\end{array}$ & $\begin{array}{l}4.14 \\
(0.75)\end{array}$ & $\begin{array}{l}0.25 \\
(0.29)^{\star}\end{array}$ & $\begin{array}{l}0.36 \\
{[-0.900} \\
\text { to } \\
-3.32]\end{array}$ \\
\hline \multicolumn{9}{|l|}{ Function } \\
\hline $\begin{array}{l}\text { ROM } \\
\text { (FIx) }\end{array}$ & $\begin{array}{l}168.33 \\
(3.37)\end{array}$ & $\begin{array}{l}170.60 \\
(4.11)\end{array}$ & $\begin{array}{l}2.26 \\
(3.69) *\end{array}$ & $\begin{array}{l}0.60 \\
{[-4.311 \text { to }} \\
-0.22]\end{array}$ & $\begin{array}{l}167.80 \\
(3.27)\end{array}$ & $\begin{array}{l}169.93 \\
(4.39)\end{array}$ & $\begin{array}{l}2.13 \\
(3.18)^{\star}\end{array}$ & $\begin{array}{l}0.55 \\
{[-0.37} \\
\text { to } \\
-2.59]\end{array}$ \\
\hline $\mathrm{ROM}(\mathrm{Ab})$ & $\begin{array}{l}163.13 \\
(5.46)\end{array}$ & $\begin{array}{l}164.73 \\
(4.78)\end{array}$ & $\begin{array}{l}1.60 \\
(3.22) *\end{array}$ & $\begin{array}{l}0.31[-3.38 \\
\text { to } 0.18]\end{array}$ & $\begin{array}{l}164.00 \\
(4.76)\end{array}$ & $\begin{array}{l}165.07 \\
(2.68)\end{array}$ & $\begin{array}{l}1.07 \\
(3.97)^{\star}\end{array}$ & $\begin{array}{l}0.27 \\
{[-3.266} \\
\text { to } \\
1.13]\end{array}$ \\
\hline K-DASH & $\begin{array}{l}31.41 \\
(8.56)\end{array}$ & $\begin{array}{l}22.54 \\
(7.55)\end{array}$ & $\begin{array}{l}8.86 \\
(5.93)^{*}\end{array}$ & $\begin{array}{l}1.09[5.57 \\
\text { to } 12.15]\end{array}$ & $\begin{array}{l}33.01 \\
(10.64)\end{array}$ & $\begin{array}{l}26.72 \\
(9.84)\end{array}$ & $\begin{array}{l}6.29 \\
(2.78)^{\star}\end{array}$ & $\begin{array}{l}0.61 \\
{[7.82} \\
\text { to } \\
8.75]\end{array}$ \\
\hline Strength & $\begin{array}{l}27.05 \\
(5.97)\end{array}$ & $\begin{array}{l}28.24 \\
(5.87)\end{array}$ & $\begin{array}{l}1.18 \\
(1.64)^{*}\end{array}$ & $\begin{array}{l}0.20[-2.09 \\
\text { to }-0.27]\end{array}$ & $\begin{array}{l}29.27 \\
(4.39)\end{array}$ & $\begin{array}{l}30.65 \\
(4.91)\end{array}$ & $\begin{array}{l}1.38 \\
(0.75)^{\star}\end{array}$ & $\begin{array}{l}0.29 \\
{[-2.43} \\
\text { to } \\
-0.34]\end{array}$ \\
\hline
\end{tabular}

\subsection{Changes in shoulder pain in the ICT and LLLT groups}

Shoulder function was assessed based on shoulder ROM, K-DASH, and rotator cuff strength. In the ICT group, shoulder flexion significantly increased by $2.27^{\circ}$ from $168.33^{\circ}$ before treatment to $170.60^{\circ}$ after treatment $(p<0.05)$, and shoulder abduction increased by $1.60^{\circ}$ from $163.13^{\circ}$ before treatment to $164.73^{\circ}$ after treatment, though statistically insignificant. The K-DASH score significantly decreased by 8.87 from 31.41 before treatment to 22.54 after treatment $(p<0.05)$, and rotator cuff strength significantly increased by $1.17 \mathrm{~kg}$ from $27.07 \mathrm{~kg}$ before treatment to $28.24 \mathrm{~kg}$ after treatment $(p<0.05)$. 
In the LLLT group, shoulder flexion significantly increased by $1.53^{\circ}$ from $167.80^{\circ}$ before treatment to $169.93^{\circ}$ after treatment $(p<0.05)$, and shoulder abduction increased by $1.07^{\circ}$ from $164.00^{\circ}$ before treatment to $165.07^{\circ}$ after treatment, though statistically insignificant. The K-DASH score significantly decreased by 6.29 from 33.01 before treatment to 26.72 after treatment $(p<0.05)$, and rotator cuff strength significantly increased by $1.37 \mathrm{~kg}$ from $29.28 \mathrm{~kg}$ before treatment to $30.65 \mathrm{~kg}$ after treatment (p $<0.05)$. There were no statistically significant differences in shoulder functions after treatment between the two groups (Table 2).

\section{Discussion}

Although there are only a few reliable tests for shoulder pain, it is determined in association with the subacromial bursa, rotator cuff tendon, and tendon of the long head of biceps muscle, which are the anatomical structures of the subacromial space (28-30). This assumption does not take into account the fact that muscle tissue may induce pain in the shoulder area (31).

A recent study on the referral of muscle pain is based on the fact that the synaptic connection of central dorsal horn neurons may be altered as a result of nociceptive input (Mense, Simons, Hoheisel, \& Quenzer, 2003).

Dorsal horn neurons have an effective and ineffective synaptic connection including afferent neurons. An effective synapse accepts information regarding trigger points and forms an existing receptive field. Local pain is moderated through this pathway. An ineffective synapse fires an insufficient potential to induce a response in the dorsal horn neuron. However, when an ineffective synapse is placed in a pathological environment, neurons stimulated by nociceptive input create a new receptive field and it is converted into an effective synapse, a process known as central sensitization. When a new receptive field emerges, non-nociceptive input in a location other than the existing location of pain can be felt as pain (32).

Trigger points of the rotator cuff may provoke local referral pain deep in the shoulder joints. As a result, shoulder pain caused by trigger points may be misunderstood as subarcomial buritis or tendinitis, and consequent inflammation-related treatment may diminish the efficacy of treatment (22). Therefore, direct treatment of MTrPs of the infraspinatus muscle can be an alternative for shoulder pain.

The ICT applied in this study reduced VAS by $49.36 \%$ and improved PPT by $8.07 \%$. LLLT reduced VAS for shoulder pain by $38.80 \%$ and improved PPT by $6.42 \%$. These results suggest that both treatments alleviate shoulder pain.

Carel Bron et al. (2011) applied manual pressure, passive muscle stretching, and cold application during stretching on trigger points of shoulder muscles (22). The results showed that VAS and K-DASH scores were significantly improved, and the number of active trigger points decreased. Carrasco (2009) reported that LLLT on trigger points of the masseter and temporalis was effective in reducing temporomandibular 
joint pain (33). Although the type of treatment used and muscle involved differed between our study and previous studies, one similarity is that the studies aimed to identify pain by treating trigger points.

Although the exact mechanism underlying the pain-reducing effects observed in this study is yet unclear, it can be understood through various hypotheses. A recent study reported that pain mechanism is related to glial cells. Microglia and astrocytes have been reported to be activated by peripheral pathological changes, including inflammation (34). Data on whether trigger points generally impact glial cells are scarce. However, because pain receptors activate glial cells, pain receptors in trigger points may have an impact on glial cells (35). During an ICT, compression induces a momentary ischemic state in the trigger points and once the compression is removed, reactive hyperemia occurs, in which increased blood flow to the muscle fibers facilitates circulation (36). LLLT controls microcirculation and increases oxygen supply to the trigger points, thereby normalizing the metabolic rate of tissues (37). The enhanced blood circulation as a result of these treatments is speculated to impact the pain receptors in the trigger points by reducing inflammation in the body and thus affecting glial cells.

In the present study, we assessed shoulder ROM (flexion, abduction), K-DASH, and rotator cuff strength to evaluate shoulder function. ICT increased the range of shoulder flexion by $1.34 \%$ and shoulder abduction by $0.98 \%$, decreased K-DASH score by $28.23 \%$, and improved rotator cuff strength by $4.39 \%$. LLLT increased the range of shoulder flexion by $1.26 \%$ and shoulder abduction by $0.65 \%$, decreased K-DASH score by $19.05 \%$, and improved rotator cuff strength by $4.71 \%$. These results show that all shoulder functions, with the exception of range of abduction, were improved. However, both ICT and LLLT seem to have clinical effects on the range of shoulder abduction, though the effect sizes are small, at 0.31 for ICT and 0.27 for LLLT.

Hains et al. (2010) applied sham compression and ICT on trigger points of the supraspinatus, infraspinatus, deltoid, and biceps brachii muscles, which led to significant improvements in shoulder pain and dysfunction index (SPADI) (21). Chow et al. (2006) applied LLLT on trigger points around the neck in patients with chronic neck pain and reported that there were therapeutic effects, with significant changes in the Neck Pain and Disability Scale (NPAD) and McGill Pain Questionnaire (MPQ) (38). The present study also confirmed improvements in shoulder functions after MTrP treatment, but our study differs in that shoulder function was assessed after treatment of MTrPs in a single muscle.

Subacromial pain reduces voluntary activity of the infraspinatus muscle and external rotation of the shoulder joint. Inhibition of the infraspinatus muscle by subacromial pain may lead to abnormal Gh joint motion and translation (39). As a result, normal muscle activation patterns may be affected, which may result in muscle weakening and motor disabilities (40) as well as reduced ROM. Lucas et al. (2010) reported that passive stretching and dry needling to reduce MTrPs led to normalized motor activation pattern within 20-30 minutes (41).

In the present study, treatment of MTrPs of the infraspinatus muscle is believed to have improved external rotation and normalized shoulder joint movement. In the long term, normal motor activation 
patterns appeared, which seems to have increased rotator cuff strength. However, these speculations are based on previous findings, so additional studies are needed to establish a theoretical mechanism.

Because there were no differences between the two groups in our study, we compared their effect sizes as well. ICT had greater effect sizes than those of LLLT, with the exception of effect sizes for VAS and rotator cuff strength. This suggests that both treatments were helpful for mitigating pain and improving shoulder function in patients with shoulder pain. Therefore, selective treatment of MTrPs of the infraspinatus muscle is effective, and ICT and LLLT could be clinically effective when used appropriately according to patient characteristics.

This study has a few limitations. First, the sample size was not sufficient to generalize the study findings. Second, the infraspinatus muscle is not the only muscle that can provoke shoulder pain and limit shoulder functions. Third, we examined the ROM of shoulder movements that are frequently used in daily life (flexion, abduction), so we could not determine external rotation, the major function of the infraspinatus muscle. Finally, due to a lack of a control group, we could not examine changes in the variables over time. Subsequent studies should address these limitations for further comparisons.

\section{Conclusion}

This study showed that ICT and LLLT were both effective on MTrPs of the infraspinatus muscle in patients with shoulder pain but could not discriminate which of the two treatments is more effective. With more diverse studies on the trigger points related to shoulder pain in the future, these treatments could be proposed as effective clinical treatments for patients with shoulder pain.

\section{Declarations}

\section{Abbreviations}

Cl: confidence interval; ICT: ischemic compression treatment; ITT: intention to treat; K-DASH: Korea version of the Disability of the Arm, Shoulder and Hand; LLLT: low-level laser therapy; LOCF: last observation carried forward; MTrPs : myofascial trigger points; PPT: pressure-pain threshold; ROM: range of motion; SD: standard deviation(SD); VAS: Visual Analogue Scale

\section{Acknowledgments}

None

\section{Authors' contributions}


This study was designed, directed, and coordinated by LSW. And PSG and CJC as the principal investigator, provided conceptual and technical guidance for all aspects of the project.

\section{Funding}

This research received no external funding.

\section{Availability of data and materials}

The data sets that will be used and/or analyzed during the current study will be available from the corresponding author on reasonable request.

\section{Ethics approval and consent to participate}

This study was approved by the Bioethics committee of Sahmyook University(IRB number: 2-1040781AB-N-01-2017063HR/ June 22, 2017). Written informed consent is obtained from all study participants prior to randomization.

\section{Consent for publication}

Not applicable.

\section{Competing interests}

The authors declare that they have no competing interests

\section{Abbreviations}

$\mathrm{Cl}$

confidence interval; ICT:ischemic compression treatment; ITT:intention to treat; K-DASH:Korea version of the Disability of the Arm, Shoulder and Hand; LLLT:Iow-level laser therapy; LOCF:last observation carried 
forward; MTrPs:myofascial trigger points; PPT:pressure-pain threshold; ROM:range of motion; SD:standard deviation(SD); VAS:Visual Analogue Scale

\section{References}

1. Perry J. Anatomy and biomechanics of the shoulder in throwing, swimming, gymnastics, and tennis. Clin Sports Med. 1983;2:247-70.

2. Sporrong H, Palmerud G, Kadefors R, Herberts P. The effect of light manual precision work on shoulder muscles-an EMG analysis. J Electromyogr Kinesiol. 1998;8:177-84.

3. Järvholm U, Palmerud G, Herberts P, Högfors C, Kadefors R. Intramuscular pressure and electromyography in the supraspinatus muscle at shoulder abduction. Clin Orthop Relat Res. 1989; (245):102-9.

4. Järvholm U, Palmerud G, Karlsson D, Herberts P, Kadefors R. Intramuscular pressure and electromyography in four shoulder muscles. J Orthop Res. 1991;9:609-19.

5. Birch L, Juul-Kristensen B, Jensen C, Finsen L, Christensen H. Acute response to precision, time pressure and mental demand during simulated computer work. Scand J Work Env Hea. 2000;26:299305.

6. Burkhart SS. Arthroscopic treatment of massive rotator cuff tears. Clinical results and biomechanical rationale. Clin Orthop Relat Res. 1991;(267):45-56.

7. Keener JD, Wei AS, Kim HM, Steger-May K, Yamaguchi K. Proximal humeral migration in shoulders with symptomatic and asymptomatic rotator cuff tears. J Bone Joint Surg Am. 2009;91:1405.

8. Oh JH, Jun BJ, McGarry MH, Lee TQ. Does a critical rotator cuff tear stage exist?: a biomechanical study of rotator cuff tear progression in human cadaver shoulders. J Bone Joint Surg. 2011;93:21009.

9. Lakemeier S, Reichelt JJ, Timmesfeld N, Fuchs-Winkelmann S, Paletta JR, Schofer MD. The relevance of long head biceps degeneration in the presence of rotator cuff tears. BMC Musculoskelet Disord. 2010;11:191.

10. Hidalgo-Lozano A, Fernández-de-las-Peñas C, Alonso-Blanco C, Ge H-Y, Arendt-Nielsen L, ArroyoMorales M. Muscle trigger points and pressure pain hyperalgesia in the shoulder muscles in patients with unilateral shoulder impingement: a blinded, controlled study. Exp Brain Res. 2010;202:915-25.

11. Simons DG. Muscular pain syndromes. Advances in Pain Research and Therapy 1990;17:1-41

12. Shah JP, Danoff JV, Desai MJ, Parikh S, Nakamura LY, Phillips TM, et al. Biochemicals associated with pain and inflammation are elevated in sites near to and remote from active myofascial trigger points. Arch Phys Med Rehab. 2008;89:16-23.

13. Fomby EW, Mellion MB. Identifying and treating myofascial pain syndrome. Phys Sportsmed. 1997;25:67-75. 
14. Cagnie B, Dewitte V, Coppieters I, Van Oosterwijck J, Cools A, Danneels L. Effect of ischemic compression on trigger points in the neck and shoulder muscles in office workers: a cohort study. $J$ Manip Physiol Ther. 2013;36:482-9.

15. Annaswamy TM, De Luigi AJ, O'Neill BJ, Keole N, Berbrayer D. Emerging concepts in the treatment of myofascial pain: a review of medications, modalities, and needle-based interventions. PM R. 2011;3:940-61.

16. Bron C, Franssen J, de Valk B. Een posttraumatische schouderklacht zonder aanwijsbaar letsel. Nederlands Tijdschrift voor Fysiotherapie. 2001;111:102-7.

17. Daub CW. A case report of a patient with upper extremity symptoms: differentiating radicular and referred pain. Chiropr Osteopat. 2007;15:10.

18. Ingber RS. Shoulder impingement in tennis/racquetball players treated with subscapularis myofascial treatments. Arch Phys Med Rehab. 2000;81:679-82.

19. Simons DG, Travell JG, Simons LS. Myofascial pain and dysfunction: the trigger point manual. Vol 1: upper half of body. London: Lippincott Williams \& Wilkins. 1999a

20. Skootsky SA, Jaeger B, Oye RK. Prevalence of myofascial pain in general internal medicine practice. West J Med. 1989;151:157.

21. Hains G, Descarreaux M, Hains F. Chronic shoulder pain of myofascial origin: a randomized clinical trial using ischemic compression therapy. J Manipulative Physiol Ther. 2010, 33(5), 362-369.

22. Bron C, De Gast A, Dommerholt J, Stegenga B, Wensing M, Oostendorp RA. Treatment of myofascial trigger points in patients with chronic shoulder pain: a randomized, controlled trial. BMC Med. 2011;9:8.

23. Momenzadeh S, Akhyani V, Razaghi Z, Ebadifar A, Abbasi M. Evaluation of the effects of intravenous and percutaneous low level laser therapy in the management of shoulder myofascial pain syndrome. J Lasers Med Sci. 2016;7:16.

24. Ravichandran P, Ponni HK, Aseer PAL. Effectiveness of ischemic compression on trapezius myofascial trigger points in neck pain. Int J Sports Phys Ther. 2016:186-192.

25. Hakgüder A, Birtane M, Gürcan S, Kokino S, Nesrin Turan F. Efficacy of low level laser therapy in myofascial pain syndrome: an algometric and thermographic evaluation. Lasers Surg Med. 2003;33:339-43.

26. Yang Y-J, Lee S-J, Choi M. Pressure pain threshold and visual analogue scale changes in the high and low energy extracorporeal shock wave. Phys Ther Rehabil Sci. 2014;3:142-7.

27. Horsley I, Herrington L, Hoyle R, Prescott E, Bellamy N. Do changes in hand grip strength correlate with shoulder rotator cuff function? Shoulder Elbow. 2016;8:124-9.

28. Bang MD, Deyle GD. Comparison of supervised exercise with and without manual physical therapy for patients with shoulder impingement syndrome. J Orthop Sports Phys Ther. 2000;30:126-37.

29. Michener LA, McClure PW, Karduna AR. Anatomical and biomechanical mechanisms of subacromial impingement syndrome. Clin Biomech. 2003;18:369-79. 
30. Steinfeld R, Valente RM, Stuart MJ. A commonsense approach to shoulder problems. Paper presented at the Mayo Clinic Proceedings.1999.

31. Travell JG, Simons DG. Myofascial pain and dysfunction: the trigger point manual. Vol. 2. London: Lippincott Williams \& Wilkins. 1983

32. Hoheisel U, Mense S, Simons DG, Yu X-M. Appearance of new receptive fields in rat dorsal horn neurons following noxious stimulation of skeletal muscle: a model for referral of muscle pain? Neurosci Lett. 1993;153:9-12.

33. Carrasco TG, Guerisoli LDC, Guerisoli DMZ, Mazzetto MO. Evaluation of low intensity laser therapy in myofascial pain syndrome. Cranio. 2009;27:243-7.

34. Watkins LR, Maier SF. Glia: a novel drug discovery target for clinical pain. Nat Rev Drug Discov. 2003;2:973.

35. Mense S. How do muscle lesions such as latent and active trigger points influence central nociceptive neurons? J Musculoskelet Pain. 2010;18:348-53.

36. Moraska AF, Hickner RC, Kohrt WM, Brewer A. Changes in blood flow and cellular metabolism at a myofascial trigger point with trigger point release (ischemic compression): a proof-of-principle pilot study. Arch Phys Med Rehab. 2013;94:196-200.

37. Ozdemir F, Birtane M, Kokino S. The clinical efficacy of low-power laser therapy on pain and function in cervical osteoarthritis. Clin Rheumatol. 2001;20:181-4.

38. Chow RT, Heller GZ, Barnsley L. The effect of $300 \mathrm{~mW}, 830 \mathrm{~nm}$ laser on chronic neck pain: a doubleblind, randomized, placebo-controlled study. Pain. 2006;124:201-10.

39. Stackhouse SK, Eisennagel A, Eisennagel J, Lenker H, Sweitzer BA, McClure PW. Experimental pain inhibits infraspinatus activation during isometric external rotation. J Shoulder Elbow Surg. 2013;22:478-84.

40. Blanco CR, de las Peñas CF, Xumet JEH, Algaba CP, Rabadán MF, de la Quintana MCL. Changes in active mouth opening following a single treatment of latent myofascial trigger points in the masseter muscle involving post-isometric relaxation or strain/counterstrain. J Bodyw Mov Ther. 2006;10: 197205.

41. Lucas KR, Rich PA, Polus BI. Muscle activation patterns in the scapular positioning muscles during loaded scapular plane elevation: the effects of latent myofascial trigger points. Clin Biomech. 2010;25:765-70.

\section{Tables}

Table 1. Participants' general characteristics 


\begin{tabular}{cccc}
\hline & ICT & LLLT & $P$ value \\
Parameter & $(n=15)$ & $(n=15)$ & (intergroup values) \\
\hline Sex (male/female) & $5 / 10$ & $3 / 8$ & 0.213 \\
Age (years) & $36.49(9.66)$ & $168.00(5.35)$ & 0.496 \\
Height (cm) & $166.26(8.11)$ & $65.47(9.23)$ & 0.539 \\
\hline Body weight (kg) & $63.06(11.74)$ & \\
\hline
\end{tabular}

ICT, ischemic compression treatment; LLLT, low level laser treatment

Values are shown as mean (standard deviation)

Table 2. Changes in shoulder pain after ICT and LLLT

\begin{tabular}{|c|c|c|c|c|c|c|c|c|}
\hline & \multicolumn{4}{|c|}{ ICT } & \multicolumn{4}{|c|}{ LLT } \\
\hline & Pre & Post & Change & $\mathrm{d}[\mathrm{CI}]$ & Pre & Post & Change & ES [CI] \\
\hline \multicolumn{9}{|l|}{ Pain } \\
\hline \multirow[t]{2}{*}{ VAS } & $5.53(1.06)$ & $2.80(0.94)$ & 2.73 & $2.54[2.0$ to 3.44$]$ & $5.53(0.92)$ & $3.33(0.72)$ & 2.20 & 2.66 [1.56 to 2.83$]$ \\
\hline & & & $(1.27)^{*}$ & & & & $(1.14)^{*}$ & \\
\hline \multirow[t]{2}{*}{ PPT } & $3.84(0.57)$ & $4.17(0.47)$ & 0.30 & $0.63[-0.53$ to & $3.89(0.61)$ & $4.14(0.75)$ & 0.25 & $0.36[-0.900$ to \\
\hline & & & $(0.41)^{*}$ & $-0.07]$ & & & $(0.29)^{*}$ & $-3.32]$ \\
\hline \multicolumn{9}{|l|}{ Function } \\
\hline ROM & 168.33 & 170.60 & 2.26 & $0.60[-4.311$ to & 167.80 & 169.93 & 2.13 & $0.55[-0.37$ to \\
\hline (Flx) & (3.37) & $(4.11)$ & $(3.69) *$ & $-0.22]$ & $(3.27)$ & $(4.39)$ & $(3.18)^{*}$ & $-2.59]$ \\
\hline \multirow[t]{2}{*}{$\mathrm{ROM}(\mathrm{Ab})$} & 163.13 & 164.73 & 1.60 & $0.31[-3.38$ to & 164.00 & 165.07 & 1.07 & $0.27[-3.266$ to \\
\hline & $(5.46)$ & $(4.78)$ & $(3.22)^{*}$ & $0.18]$ & $(4.76)$ & $(2.68)$ & $(3.97)^{*}$ & $1.13]$ \\
\hline \multirow[t]{2}{*}{ K-DASH } & 31.41 & 22.54 & 8.86 & $1.09[5.57$ to & 33.01 & 26.72 & 6.29 & $0.61[7.82$ to 8.75$]$ \\
\hline & $(8.56)$ & $(7.55)$ & $(5.93) *$ & 12.15] & $(10.64)$ & $(9.84)$ & $(2.78)^{*}$ & \\
\hline \multirow[t]{2}{*}{ Strength } & 27.05 & 28.24 & 1.18 & $0.20[-2.09$ to & 29.27 & 30.65 & 1.38 & $0.29[-2.43$ to \\
\hline & (5.97) & (5.87) & $(1.64)^{*}$ & $-0.27]$ & (4.39) & $(4.91)$ & $(0.75)^{*}$ & $-0.34]$ \\
\hline
\end{tabular}

$* P<0.05$

K-DASH: Korea version of the Disability of the Arm, Shoulder, and Hand; CI, confidence interval; ES, effect size 


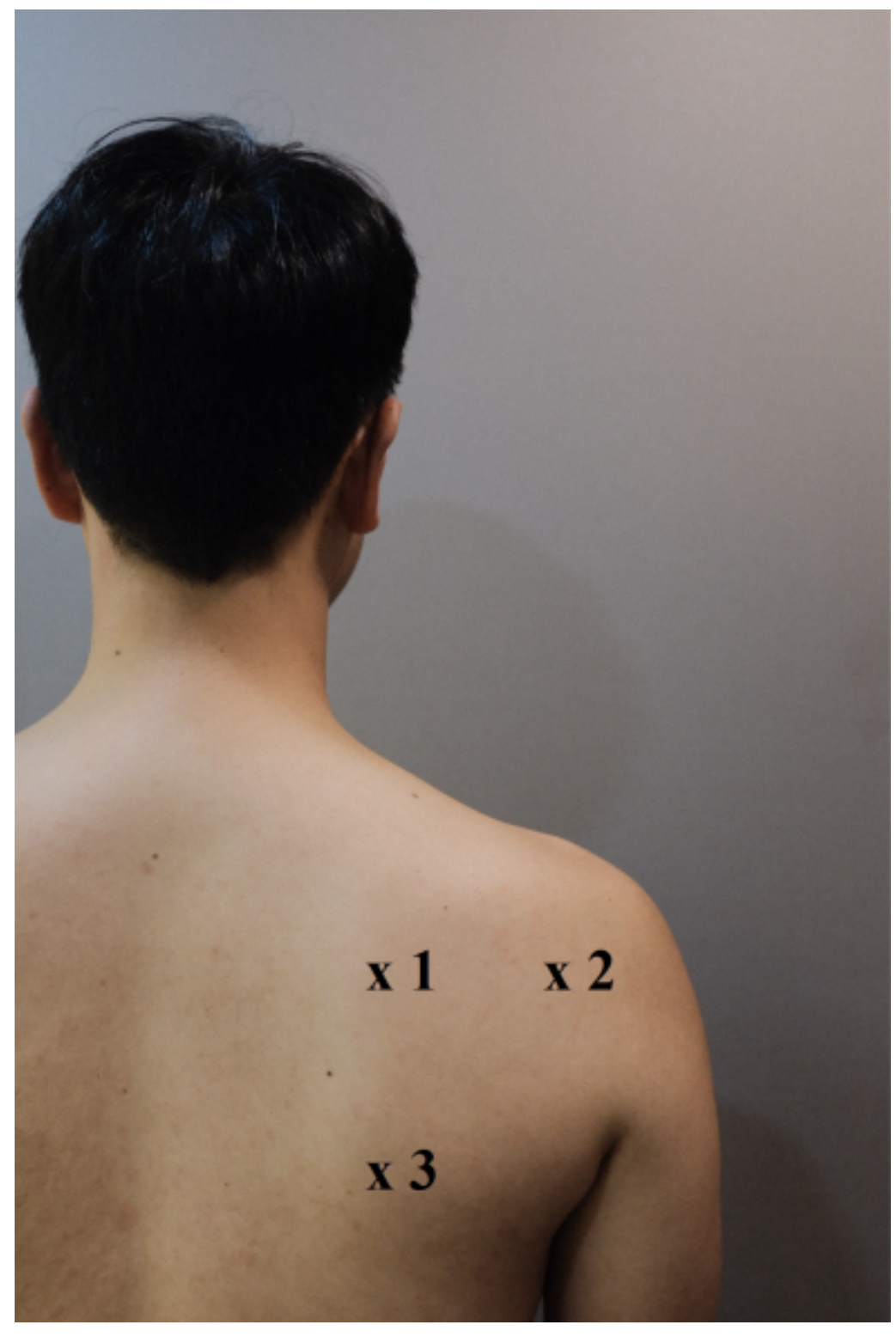

Figure 1

Infraspinatus trigger point 


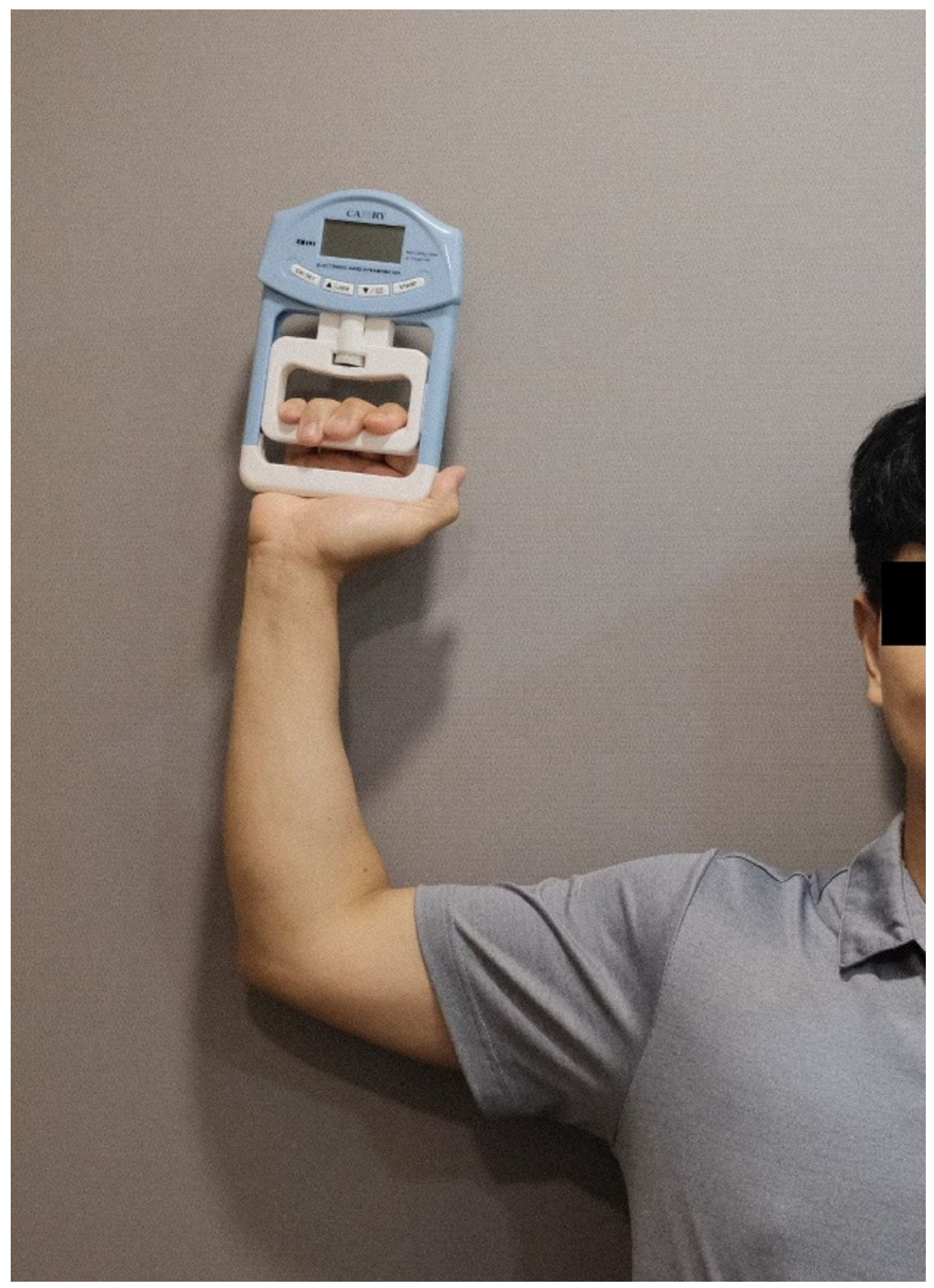

Figure 2

Rotator cuff strength measurement 